\title{
26477 - EFFECT OF CPB ON RAT RENAL GENE EXPRESSION AND BLOOD FLOW
}

\section{Peter Darby MD PhD, Francoise Briet, PhD; Alana Harrington, HBSc; Gregory Hare, David Mazer, MD; St. Michael's Hospital, Toronto, ONTARIO, Canada}

INTRODUCTION: Renal failure (RF) occurs in up to $30 \%$ of patients undergoing cardiopulmonary bypass (CPB). Patients requiring dialysis have a 20 -fold increase in mortality ${ }^{1}$. Mechanisms of RF are not completely understood, although animal models have potentially identified anemia, hypoxia, ischemia, and acute inflammation ${ }^{2}$. We investigated in rats the effect of $\mathrm{CPB}$ on renal gene expression using microarray analysis and on renal blood flow using laser doppler probes.

METHODS: With ACC approval, Sprague-Dawley rats were anesthetized with ketamine and isoflurane. Study rats underwent normothermic CPB for 1 hour with a neonatal membrane oxygenator. Sham animals were instrumented but did not undergo CPB. Animals were sacrificed the next day and RNA was extracted from renal cortex and medulla. In separate experiments, OxyFlo laser doppler microvascular perfusion probes (Oxford Optronix) were placed under direct vision to measure relative blood flow in renal cortex and medulla. Gene expression was measured using Affymetrix GeneChip Rat 230.2, GeneSpring filtering, and GeneSifter analysis. A 2-fold change in gene expression compared to sham was considered significant. Physiologic data was analyzed using ANOVA.

RESULTS: There were no significant differences between groups in physiologic variables. Blood flow data were normalized to pre- $\mathrm{CPB}$, expressed as percent $\pm \mathrm{SD}$. During CPB, blood flow was unchanged in both cortex $(95 \pm 37 \%)$ and medulla $(96 \pm 18 \%)$ $(n=4)$. Microarray analysis identified 2-fold changes in the expression of 787 genes in cortex and 883 in medulla $(n=2)$. Of these genes, over $50 \%$ were involved in physiological processes: metabolism (195 vs 161 genes, cortex vs medulla), stress response $(43,36)$, inflammation $(11,10)$, and nitric oxide pathway $(5,1)$. Data for selected genes associated with hypoxia, ischemia and inflammation are shown in the table, expressed as fold-change compared to sham (mean $\pm \mathrm{SD}$ ). Of genes associated with hypoxia and ischemia, kidney injury molecule 1 (KIM-1) was significantly up-regulated while neutrophil gelatinase-associated lipocalin (NGAL) was significantly downregulated. Up-regulation of inflammation-related genes also occurred after CPB. These include tumor necrosis factor (TNF) receptor-12, glycosylation-dependent cell adhesion molecule-1 (GlyCAM-1), and ICAM-1.

DISCUSSION: In this model, CPB was associated with altered regulation of genes associated with mechanisms of RF. 24 hours post-CPB, acute inflammatory genes and KIM-1, a marker of acute ischemic injury, were significantly up-regulated despite maintenance of renal blood flow during CPB. Future research will identify the cellular localization and time course of renal gene expression, and the effect of other common interventions during $\mathrm{CPB}$. This will further enhance our understanding of the mechanism of renal dysfunction associated with $\mathrm{CPB}$.

REFERENCES:

1. Br J Anaesth 2005 95:20-32

2. Curr Opin Crit Care 2002 8:526-534 


\begin{tabular}{|c|c|c|}
\hline Gene Expression & Renal Contex & RENAL MEdulla \\
\hline Hypoxia/schemia & & \\
\hline KIM-1 & $13.16 \pm 3.40$ & $12.15 \pm 2.36$ \\
\hline NGAL & $0.26 \pm 0.06$ & $0.50 \pm 0.45$ \\
\hline Inflammation & & $1.31 \pm 0.09$ \\
\hline ICAM-1 & $2.59 \pm 0.10$ & $3.56 \pm 1.33$ \\
\hline GlyCAM-1 & $0.67 \pm 0.23$ & $3.35 \pm 1.67$ \\
\hline TNF Receptor-12 & $4.11 \pm 2.36$ & \\
\hline
\end{tabular}

Values indicate fold-change in gene expression compared to sham (mean $\pm \mathrm{SD}$ ). 


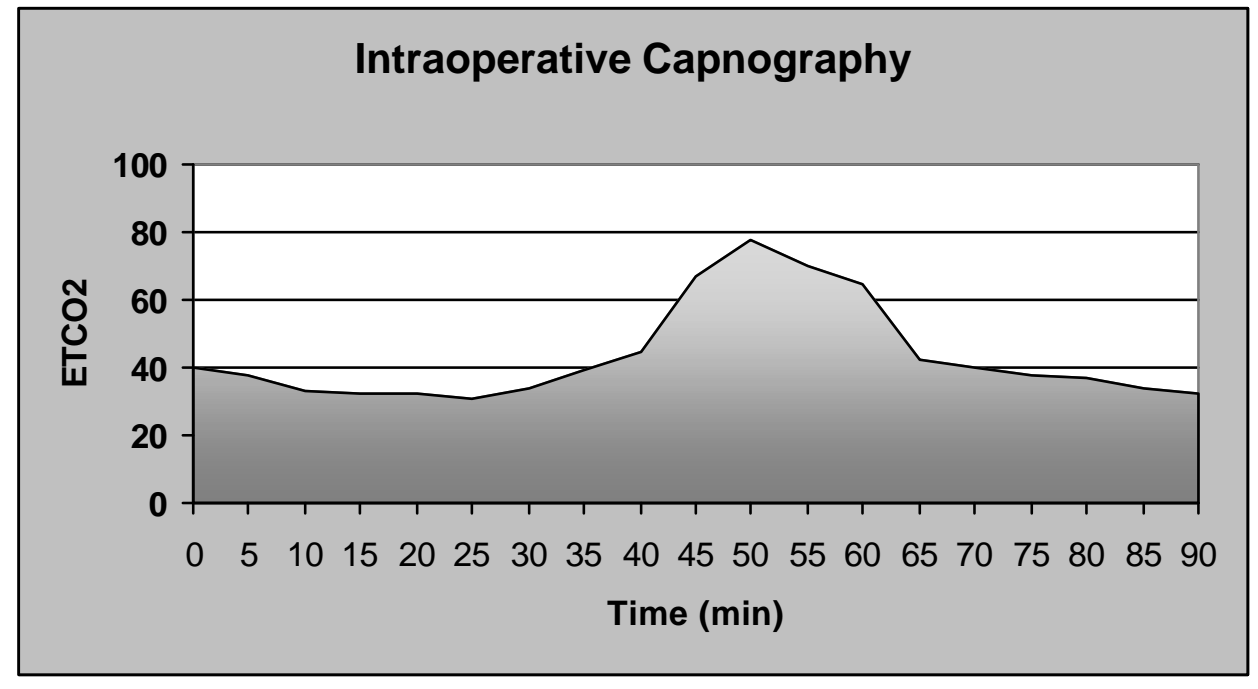

Figure 1: Intraoperative capnography demonstrating the increase of end-tidal $\mathrm{CO} 2$ during endoscopic saphenous vein harvesting. 